\title{
Implementasi Routing Terdistribusi pada Mobile AD HOC Networks (MANETS) untuk Sistem Komunikasi Taktis
}

\author{
Shelvi Eka Tassia \\ Teknik Informatika, Universitas Pamulang, Jl. Raya Puspitek no. 46, Serpong, Tangerang Selatan, \\ Indonesia \\ shelvi.tassia25@gmail.com
}

\begin{abstract}
Military communication, known tactical communications. Tactical communications support military operations is the region that does not have a fixed network infrastructure. Appropriate technology to support performance of tactical communication is Mobile Ad Hoc Networks (MANETs). Node in MANET has dynamic characteristics that will significantly influence the composition of the network topology. In tactical Mobile Ad Hoc Networks, problems that occur is the vulnerability to changes in the network topology due to node mobility. The solution face this problems is the routing protocol is suitable for use in MANET. In this study, used an approach in terms of distributed routing mechanism. In distributed routing mechanism, each node informed about the status of other nodes in the same network, and storage the information is within their local database respectively. TORA and AODV can support this mechanism, so in this study two of routing protocols will be compared in terms of dynamic adaptability, routing overhead, end-to-end delay and throughput. From this research, AODV produce better performance than TORA. For the speed of $10 \mathrm{~m} / \mathrm{s}$, the measurement of end-to-end delay is the smallest $1245.376 \mathrm{~ms}$, increase in throughput of $74.363 \%$ and the adaptability of 30.179. But the routing overhead generated greater, amounting 1359.
\end{abstract}

Keywords : node mobility, distributed routing, TORA, AODV

\section{Pendahuluan}

Jaringan komunikasi dalam operasi militer dikenal dengan istilah sistem komunikasi taktis. Sistem komunikasi ini terus mengalami perkembangan dalam operasi khusus, logistik, serta komando dan kontrol. Sistem komunikasi ini berbeda dengan sistem komunikasi pada jaringan komersial. Perbedaan mendasar antara sistem komunikasi taktis dan jaringan komersial terletak pada kendala keamanan, mobilitas user, topologi yang dinamis, kebutuhan anti-jamming, serta jarak transmisi yang pendek (Elmasry, 2010; Gohari dkk, 2011). Tidak adanya infrastruktur yang tetap pada jaringan komunikasi militer mengakibatkan sistem komunikasi ini lebih kompleks bila dibandingkan dengan jaringan komunikasi komersial pada umumnya.

Teknologi yang sesuai dan dapat mendukung sistem komunikasi taktis ini adalah Mobile Ad Hoc Networks atau yang di kenal dengan istilah MANETs (Elmasry, 2010; Maseng dkk., 2009). Teknologi ini terdiri dari perangkat keras yang disebut sebagai "node" yang dapat berpindah kemana saja. Pada teknologi MANETs setiap node bergerak tanpa adanya jaringan infrastruktur yang tetap dan merupakan jaringan wireless multihop (Adam dan Ismail, 2010). Setiap node dapat berkomunikasi secara langsung dengan node lainnya jika berada dalam jangkauan wireless, tetapi jika node tersebut berada diluar jangkauan wireless maka harus berkomunikasi menggunakan rute multihop melalui node lain yang berada dalam jaringan (Thoppian dan Prakash, 2006).

Sifat MANETs yang self-forming dan selfhealing yang artinya setiap unit yang berwenang dapat bergabung, meninggalkan dan bergabung kembali kedalam jaringan tanpa di perlukan intervensi manual, sangat menguntungkan bagi sistem komunikasi militer (Burbank dan Chimento, 2006). Peran MANETs sangat penting dalam mewujudkan Global Information Grid (GIG). Dalam operasi militer, sistem keanggotaan yang bersifat dinamis tetapi tetap terbatas untuk keanggotaan yang memiliki kewenangan merupakan sifat ideal yang harus dimiliki oleh MANETs. MANETs dapat beroperasi sendiri ataupun terhubung ke GIG tergantung pada misi dan lingkungan tetapi tidak merubah kinerja dan kemampuan fungsionalitas jaringan komunikasi.

Rentannya perubahan topologi jaringan komunikasi yang disebabkan oleh pergerakan node yang menjauhi rute utama yang telah ditentukan ataupun karena adanya node yang rusak ataupun 
hancur pada teknologi MANETs menimbulkan permasalahan. Untuk mengatasi permasalahan yang terjadi pada taktikal MANETs, penulis melakukan penelitian mengenai protokol routing yang tepat untuk diimplementasikan dalam taktikal MANETs.

Dalam penelitian ini, di gunakan suatu pendekatan dalam hal protokol routing yaitu mekanisme routing terdistribusi. Dimana pada mekanisme ini setiap node diinformasikan mengenai status jaringan dari node lain dalam jaringan yang sama, dan penyimpanan informasi berada dalam database lokal mereka masingmasing. Dengan adanya mekanisme routing terdistribusi ini, semua node mampu mempertahankan dan memperbarui tabel routing mereka melalui beberapa algoritma independen. Selain itu, routing terdistribusi memiliki kemampuan dalam hal adaptability, scalability dan kalkulasi tabel routing yang optimal. Diantara beberapa jenis routing protokol yang telah diusulkan untuk MANET, TORA dan AODV dapat mendukung mekanisme routing terdistribusi tersebut, sehingga dalam penelitian ini kedua protokol routing tersebut akan dibandingkan dalam hal dynamic adaptability, routing overhead, endto-end delay dan throughput untuk menemukan metode yang sesuai dalam hal mengatasi perubahan topologi jaringan akibat dari mobilitas node, yang disebabkan adanya node yang menjauhi rute awal atau adanya node yang rusak ataupun hancur.

\section{Metode Penelitian}

Model penelitian didasarkan pada mekanisme routing yang terdistribusi. Pada routing terdistribusi, setiap node diinformasikan mengenai status jaringan dari node lain dalam jaringan yang sama, dan penyimpanan informasi berada dalam database lokal masing-masing node. Berdasarkan pengumpulan informasi tersebut, setiap node secara individu akan mengeksekusi algoritma routing yang tepat untuk mengkalkulasi tabel routing mereka sendiri. Dalam periode updating selanjutnya, semua node akan menginformasikan mengenai informasi routing terbaru mereka kesemua node tetangga. Singkatnya, dibawah mekanisme routing terdistribusi, semua node mampu mempertahankan dan memperbarui tabel routing mereka melalui beberapa algoritma independen.

Dalam lingkungan taktis, dibutuhkan suatu protokol routing yang adaptif yang mampu menemukan rute yang benar dalam lingkungan yang dinamis, serta mampu beradaptasi terhadap perubahan topologi dalam jaringan. Agar protokol routing on demand (reactive) dapat beradaptasi dengan cepat terhadap perubahan topologi dalam jaringan, diperlukan penambahan algoritma terdistribusi pada protokol routing. Dengan adanya algoritma tersebut, ketika kegagalan link terdeteksi algoritma ini akan memberitahukan node tetangga yang dipilih mengenai kegagalan link sehingg informasi mengenai kegagalan link dapat secara cepat disebarkan keseluruh node yang terjangkau yang perlu diberitahu.

\subsection{Distributed routing pada AODV}

Mobilitas node dalam teknologi MANETs yang dapat berubah sewaktu-waktu dapat berpengaruh dalam topologi jaringan, yang mengakibatkan putusnya jalur komunikasi. Salah satu karakteristik protokol routing AODV yang terkait mobilitas node adalah penyediaan rute pengiriman paket data. Dalam tabel routingnya, protokol routing AODV hanya menyediakan satu rute komunikasi dari node pengirim (sumber) ke node penerima (tujuan). Ketika rute komunikasi tersebut terputus, akibat dari mobilitas node yang berakibat pada paket loss ataupun paket routing yang terlibat dalam proses pencarian rute (route discovery).

Ilustrasi pengiriman paket data ditunjukkan oleh gambar 1. Node S diidentifikasikan sebagai node yang mengirimkan paket data sedangkan node D diidentifikasikan sebagai node penerima paket data. Sebelum proses pengiriman paket data berlangsung, node $S$ melakukan proses pencarian rute terlebih dahulu. Proses pencarian rute dilakukan dengan menyebarkan paket RREQ ke seluruh node terdekat yang berada dalam jaringan (node tetangga). Node tetangga atau yang disebut sebagai intermediate node menyebarkan paket RREP jika node tersebut memiliki informasi mengenai node penerima dalam tabel routingnya. Jika tidak, intermediate node tersebut menyebarkan ulang paket RREQ ke intermediate node terdekat setelah menambahkan nilai hop counter. Proses tersebut terus berulang hingga rute ke node tujuan terbentuk. Rute RREQ yang pertama mencapai node $\mathrm{D}$ disimpan sebagai jalur balik. Proses terakhir ketika node D menerima paket RREQ, maka node tersebut menyebarkan paket RREP dan dikirimkan melalui jalur balik yang telah terbentuk, sehingga proses pengiriman paket data dapat segera dilakukan. Pada protokol routing AODV konvensional, sequence number dan hop count menjadi dasar dalam proses pencarian rute. Permasalahan terjadi ketika salah satu node dalam jalur balik bergerak menjauhi rute utama yang telah terbentuk, seperti yang ditunjukkan dalam gambar 2. Mobilitas node ini dapat menyebabkan putusnya jalur pengiriman paket data yang sedang 
berlangsung. Proses pencarian rute baru kembali oleh node pengirim harus dilakukan protokol routing AODV agar paket data tetap sampai ke node penerima. Proses ini dapat menghasilkan jeda (delay) yang besar yang dapat mengurangi kemampuan protokol routing AODV dalam hal adaptasi terhadap perubahan topologi jaringan.

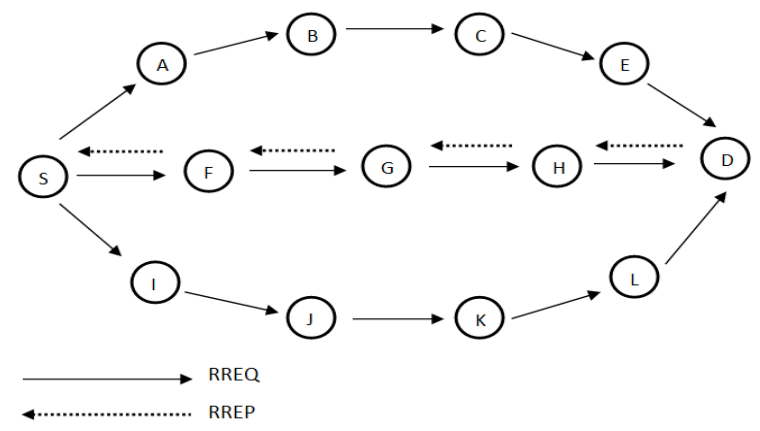

Gambar 1. Proses pencarian rute

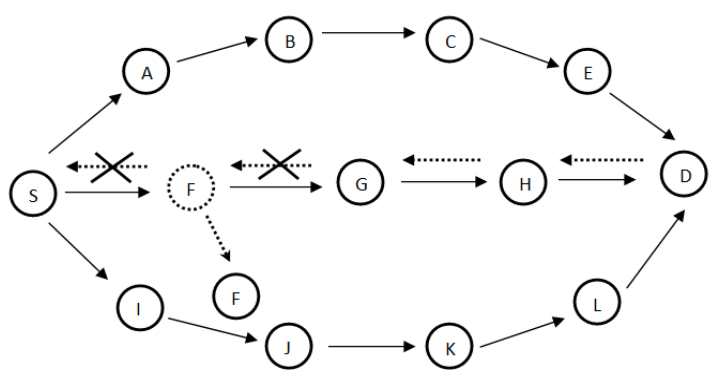

Gambar 2. Rute terputus akibat pergerakan node

Algoritma routing terdistribusi yang diterapkan pada protokol routing AODV menghasilkan sejumlah rute alternatif dalam tabel routingnya yang nantinya digunakan untuk mengirimkan paket data dari node pengirim ke node penerima. Ketika terjadi perubahan susunan topologi jaringan yang disebabkan oleh pergerakan node dan berakibat pada terputusnya rute selama proses pengiriman paket data, node pengirim tidak perlu melakukan proses pencarian rute baru kembali, tetapi dapat langsung menggunakan rute alternatif yang telah ada dalam tabel routing nya. Dalam metode routing terdistribusi ini, proses pencarian rute alternatif, nilai sequence number dan hop count tetap menjadi dasar dalam pencarian rute alternatif. Tabel routing diupdate apabila node sumber menerima lebih dari satu RREP. Node sumber menghapus paket RREP yang lama jika destination sequence number paket RREP yang ada pada tabel routing nya lebih kecil daripada destination sequence number pada paket RREP yang baru. Nilai sequence number yang lebih besar pada paket RREP menunjukkan adanya rute yang lebih baru. Tetapi sebaliknya, jika nilai hop count pada paket RREP yang baru lebih kecil daripada nilai hop count RREP yang ada pada tabel routing node sumber, menunjukkan bahwa paket RREP yang baru memiliki rute yang lebih pendek. Seperti yang ditunjukkan pada gambar 3, ketika rute utama terputus akibat mobilitas node, node sumber dapat langsung menggunakan rute alternatif yan telah disimpan dalam tabel routing nya. Hal ini dapat menghasilkan delay yang lebih kecil sehingga mampu meningkatkan kemampuan protokol routing AODV dalam beradaptasi terhadap perubahan topologi jaringan.

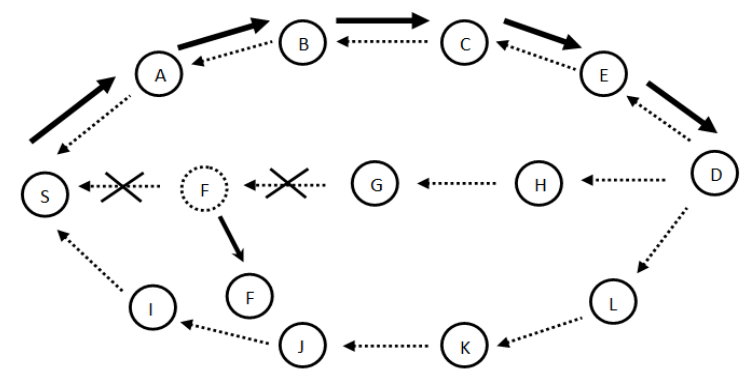

Gambar 3. Pembentukan rute alternatif

\subsection{Distributed routing pada TORA}

TORA merupakan protokol routing yang efisien, sangat adaptif dan merupakan algoritma routing terdistribusi yang scalable yang didasarkan pada konsep link reversal (pembalikan link). Protokol routing TORA diusulkan untuk jaringan yang memiliki mobilitas yang tinggi dan untuk jaringan wireless multihop. Fitur unik pada protokol routing TORA konvensional adalah memiliki beberapa rute (multiple routes), sehingga dapat mempertahankan komunikasi ke node tujuan ketika terjadi perubah an topologi dalam jaringan. Protokol routing ini akan beraksi jika semua rute yang ada dalam tabel routing-nya hilang atau rusak. Mekanime pencarian rute pada TORA sama seperti sistem water supplying. Hubungan komunikasi antara node dianggap sebagai node penghubung dimana paket data yang dikirimkan diperlakukan sebagai aliran air, seperti pada gambar 4. Dalam jaringan setiap node akan memelihara "height" untuk setiap tujuan masing-masing. Protokol routing TORA akan mengirimkan paket data dari node upstream, yaitu node yang memiliki nilai height yang tinggi ke node downstream, yaitu node yang memiliki height yang rendah. Karakter pemilihan downstream selalu pada intermediate node yang memiliki hop count terkecil atau minimum ke node tujuan.

Dengan hanya menggunakan parameter upstream dan downstream sebagai cara untuk 
pengiriman paket data, protokol routing TORA akan memiliki kelemahan, yaitu tidak mempertimbangkan beban dari masing-masing node yang digunakan sebagai next hop (intermediate hop). Hal ini akan berdampak pada kinerja jaringan, salah satunya adalah delay yang dihasilkan. Dengan menggunakan metode routing terdistribusi yang akan diterapkan pada protokol routing TORA, kriteria pemilihan next hop, yaitu node yang digunakan sebagai penghubung ke node tujuan, bukan hanya berdasarkan nilai height terendah, tetapi juga memperhitungkan node lain yang tidak pernah digunakan sebagai next hop. Sehingga proses pencarian rute tidak selalu mencari jalur yang terpendek, tetapi juga berdasarkan beban dari masing-masing node. Penambahan metode routing terdistribusi yang diterapkan pada protokol routing TORA meliputi tiga hal, yaitu:

1. Membuat variable baru untuk counter pada setiap node agent.

2. Proses update counter pada saat digunakan sebagai netx hop.

3. Pencarian next hop juga melibatkan node yang memiliki counter yang rendah.

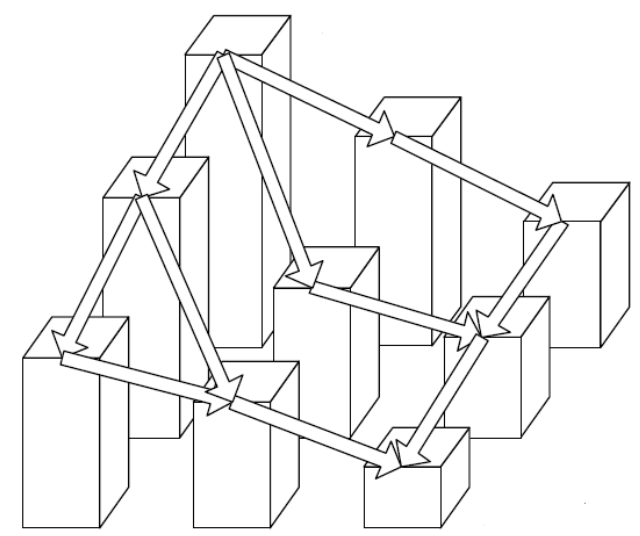

Gambar 4. Mekanisme protokol routing TORA

\section{Rancangan Penelitian}

Rancangan penelitian dibagi menjadi dua skenario penelitian. Masing-masing skenarionya akan diterapkan tiga parameter penelitian yang digunakan dalam evaluasi kinerja protokol routing yang dibandingkan.

Tabel 1. Skenario penelitian

\begin{tabular}{|l|c|}
\hline Skenario & $\begin{array}{c}\text { Perbandingan kinerja protokol } \\
\text { routing }\end{array}$ \\
\hline Skenario 1 & AODV dan TORA \\
\hline Skenario 2 & $\begin{array}{c}\text { AODV+dist.routing dan } \\
\text { TORA+dist.routing }\end{array}$ \\
\hline
\end{tabular}

\subsection{Desain simulasi}

Desain simulasi menggunakan Network Simulator 2 (NS2) untuk mengevaluasi kinerja dari protokol routing AODV dan TORA baik yang menggunakan metode konvensional ataupun metode routing terdistribusi. Tabel 2. menunjukkan spesifikasi umum simulasi yang digunakan dalam penelitian.

Tabel 2. Spesifikasi umum simulasi

\begin{tabular}{|l|l|}
\hline Parameter & Jenis \\
\hline Frekuensi & VHF \\
\hline Model Antenna & Omnidirectional \\
\hline Kanal & Wireless \\
\hline Network & Ad hoc \\
\hline Radio propagasi & Two Ray Ground \\
\hline MAC & 802.11 \\
\hline Tipe Link Layer & CSMA/CA \\
\hline
\end{tabular}

\subsection{Topologi jaringan simulasi}

Topologi jaringan yang digunakan dalam simulasi ini dibagi menjadi tiga jenis topologi yang berbeda untuk setiap protokol routing-nya dengan area simulasi 600 meter x 600 meter seperti pada gambar 5. Pada topologi jaringan simulasi (a) node sumber adalah node 0 dan yang menjadi node tujuan adalah node 10 , sedangkan pada topologi jaringan simulasi (b) dan (c) yang bertindak sebagai node sumber adalah node 6 dan node tujuan adalah node 2 . Pada masing-masing topologi terdiri dari 11 node yang dibagi menjadi 2 kategori, yaitu fixed node dan mobile node.

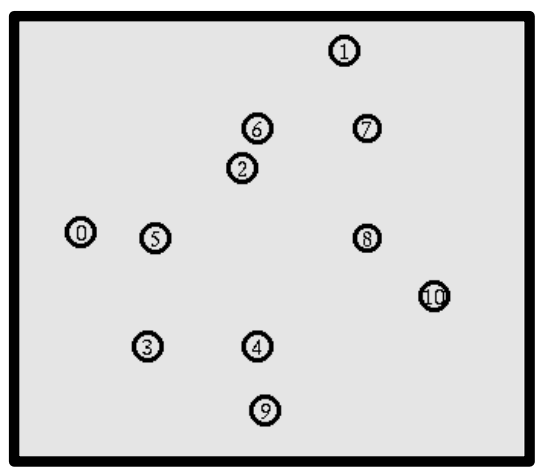

Gambar 5(a). Topologi A

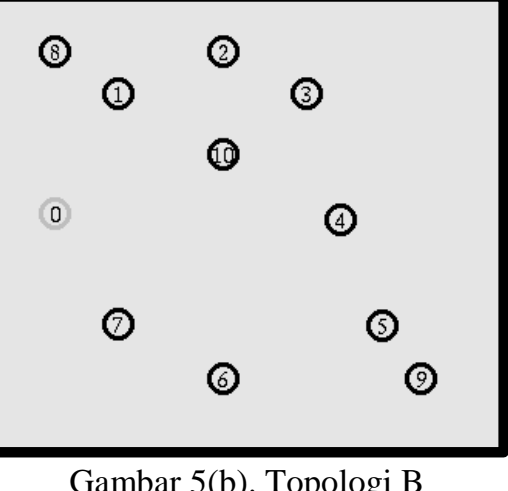

Gambar 5(b). Topologi B 


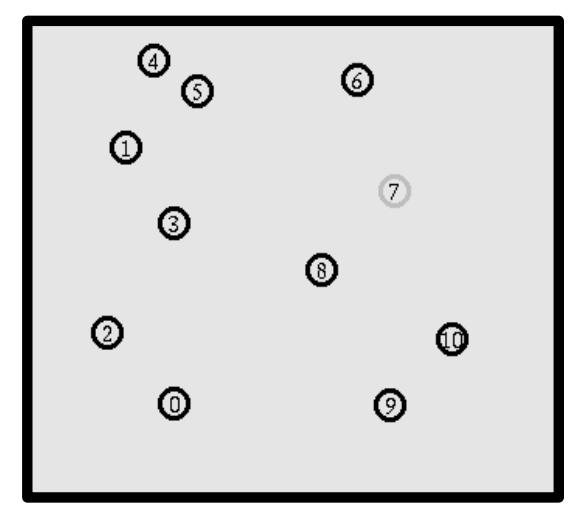

Gambar 5(c). Topologi C

Kecepatan gerak pada mobile node dibagi menjadi tiga jenis kecepatan yang berbeda yaitu 10 $\mathrm{m} / \mathrm{s}, 20 \mathrm{~m} / \mathrm{s}$ dan $30 \mathrm{~m} / \mathrm{s}$. Untuk ringkasan parameter simulasi pada ketiga jenis topologi jaringan pada masing-masing protokol routing ditunjukkan pada tabel 3.

Tabel 2. Parameter simulasi

\begin{tabular}{|l|l|}
\hline Parameter & Jenis \\
\hline Protokol routing & AODV dan TORA \\
\hline Jumlah node & 11 \\
\hline Jenis node & Fixed dan mobile \\
\hline Ukuran topologi & $600 \mathrm{~m}$ x 600 m \\
\hline $\begin{array}{l}\text { Jenis pergerakan } \\
\text { node }\end{array}$ & $\begin{array}{l}\text { RandomWayPoint } \\
\text { Model }\end{array}$ \\
\hline Trafik sumber & CBR \\
\hline Ukuran paket & 1000 \\
\hline Data-rate & 128 \\
\hline
\end{tabular}

\section{Hasil dan Pembahasan}

Hasil pengujian dilakukan berdasarkan skenario yang telah ditetapkan. Pembahasan setiap skenario dilakukan pada sub-sub berikutnya.

\subsection{Skenario 1}

Evaluasi kinerja pada skenario 1 akan membandingkan dua jenis protokol routing AODV dan TORA dengan metode konvensional. Berikut adalah analisis hasil pengukuran terhadap empat variable penelitian yang dibandingkan.

\subsubsection{End-to-End Delay}

Dari grafik pengukuran yang ditunjukkan oleh gambar 6. dapat dilihat bahwa protokol routing AODV konvensional menghasilkan nilai end-to-end delay yang lebih besar. Hal ini disebabkan karena protokol routing AODV yang memiliki satu rute untuk satu tujuan dalam tabel routingnya menjadi kelemahan protokol routing ini. Pada saat rute yang digunakan untuk pengiriman paket data antara node pengirim dan node penerima terputus yang disebabkan oleh node rusak atau menjauhi rute awal, node pengirim harus melakukan proses pencarian rute (route discovery) baru kembali. Proses pencarian rute ini akan menghasilkan delay terbesar dalam proses pengiriman paket data. Ketika node sumber membroadcast RREQ ke node tetangganya atau yang disebut dengan intermediate node, node ini akan memerlukan waktu yang lebih lama untuk mengekstrak informasi yang ada didalam paket RREQ sebelum mengirimkan paket RREP ke node sumber.

Berbeda halnya dengan protokol routing TORA konvensional yang memiliki kemampuan multiroute, yaitu memiliki beberapa rute alternatif dalam tabel routing nya. Sehingga ketika terjadi perubahan topologi jaringan yang mengakibatkan rusaknya rute utama, protokol routing ini langsung menggunakan rute alternatif yang telah tersedia sebelumnya pada tabel routing tanpa mengulang proses route discovery.

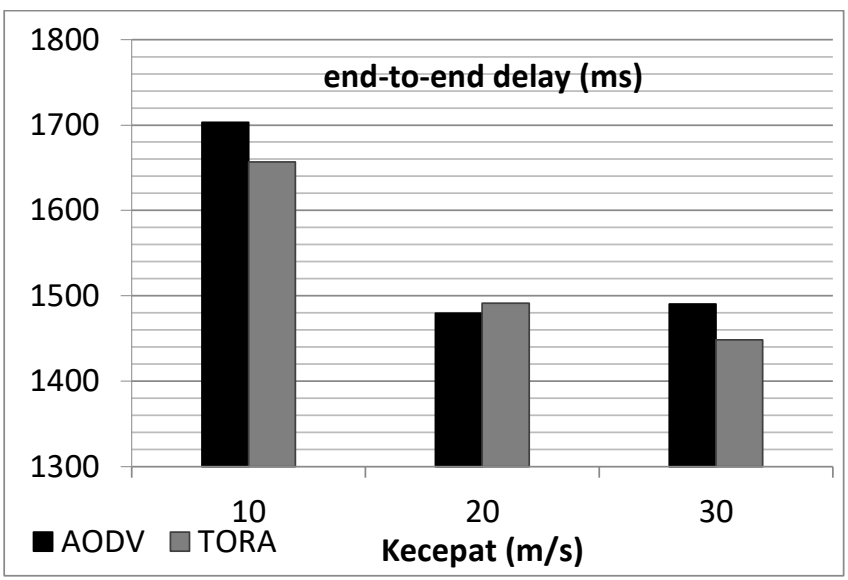

Gambar 6. End-to-end delay skenario 1

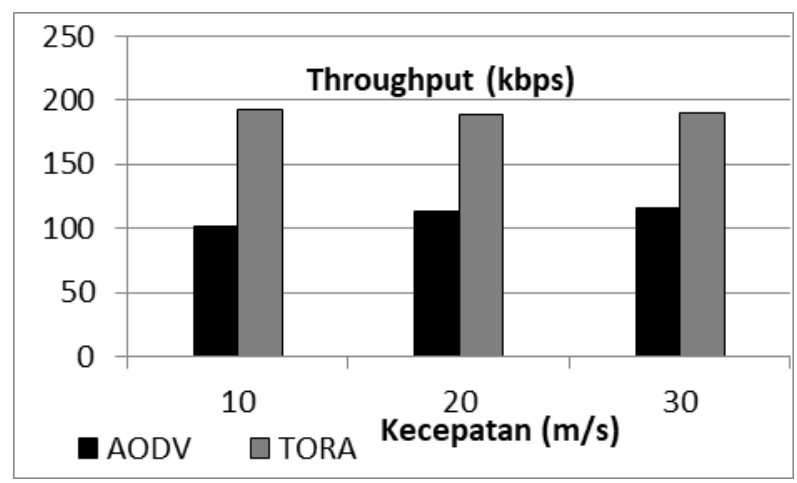

Gambar 7. Throughput skenario 1

\subsubsection{Throughput}

Pada grafik pengukuran throughput yang ditujukkan oleh gambar 7. terlihat bahwa protokol routing TORA konvensional menghasilkan nilai throughput yang lebih tinggi dibandingkan protokol routing AODV konvensional pada setiap kecepatannya. Pada saat rute pengiriman paket data terputus dari node pengirim ke node tujuan, 
protokol routing TORA akan langsung menggunakan rute alternatif yang tersimpan dalam tabel routing-nya tanpa perlu melakukan proses route discovery kembali sehingga jalur forward yang terputus dapat diminimalisasi dan loss paket dapat berkurang.

\subsubsection{Routing Overhead}

Pengukuran routing overhead dilakukan dengan cara menjumlah seluruh paket routing yang dikirimkan selama proses pengiriman paket data. Hasil pengukuran routing overhead pada skenario 1 ditunjukkan pada gambar 8 .

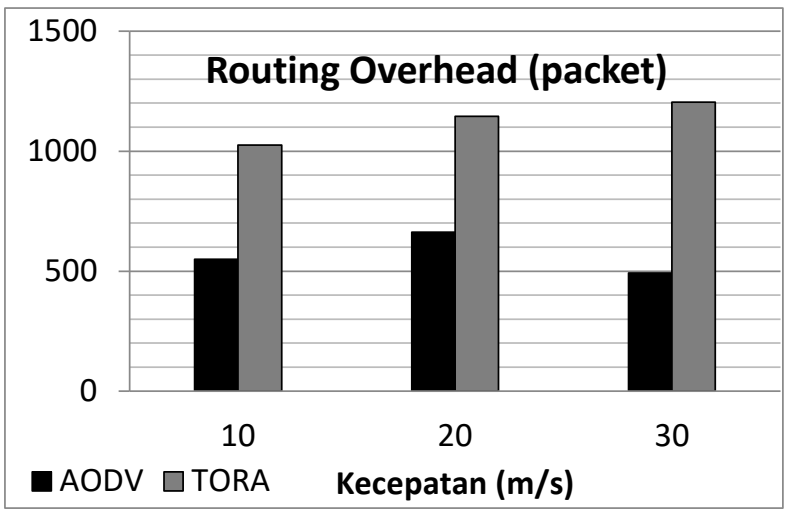

Gambar 8. Routing overhead skenario 1

Protokol routing TORA konvensional menghasilkan routing overhead yang lebih besar. Pada protokol routing ini, ketika terjadi kerusakan rute akibat mobilitas node, node sumber akan mengirimkan pesan route error keseluruh node tetangganya. Hal ini akan menyebabkan peningkatan routing overhead yang disebabkan adanya beberapa rute yang digunakan sebagai rute alternatif dalam proses pengiriman paket data. Selain itu, paket HELLO yang dihasilkan protokol routing TORA konvensional juga memberikan kontribusi dalam peningkatan routing overhead.

Berbeda halnya dengan protokol routing AODV konvensional yang menghasilkan routing overhead lebih kecil dikarenakan protokol routing ini hanya memiliki satu rute untuk satu tujuan dalam tabel routingnya. Ketika node sumber membroadcast RREQ ke setiap node tetangga yang berada dalam jangkauan transmisinya, dan kemudian menerima RREP dari beberapa node tetangga yang memiliki informasi mengenai node tujuan, node sumber akan memilih satu rute tertentu berdasarkan nilai sequence number terbesar dari RREP yang masuk kedalam tabel routing node sumber dan berdasarkan nilai hop count yang terkecil. RREP yang memiliki nilai sequence number terkecil ataupun yang memiliki nilai hop count terbesar akan dihapus dalam tabel routing node sumber.

\subsubsection{Dynamic Adaptability}

Pengukuran dynamic

adaptability berdasarkan pada hasil pengukuran throughput dan route acquisition time. Waktu yang dibutuhkan oleh node pengirim untuk menemukan rute dalam proses pengiriman paket data disebut sebagai route acquisition time. Hasil pengukuran route acquisition time ditunjukkan pada gambar 9 .

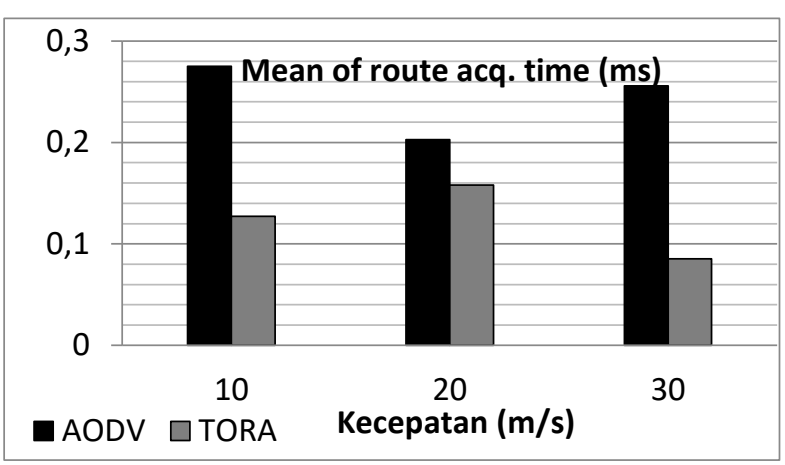

Gambar 9. Route Acquisition time skenario 1

Pengukuran route acquisition time dilakukan dengan cara mencari selisih waktu antara pengiriman paket RREP yang merupakan balasan dari paket RREQ yang dikirimkan oleh node sumber. Pengiriman paket RREP oleh intermediate node menunjukkan bahwa jalur reverse (jalur balik) untuk pengiriman paket data telah terbentuk.

Dari gambar 9. dapat dilihat bahwa waktu yang dibutuhkan protokol routing TORA konvensional untuk menemukan kembali rute pengiriman paket data yang terputus sebelumnya akibat mobilitas node lebih cepta dibandingkan dengan protokol routing AODV konvensional. Proses route discovery yang dilakukan kembali oleh protokol routing AODV konvensional untuk menemukan rute baru menyebabkan waktu route acquisition time yang lebih lama.

Dari hasil perhitungan didapatkan bahwa protokol routing TORA konvensional memiliki kemampuan adaptasi yang lebih baik dibandingkan protokol routing AODV konvensional seperti yang ditunjukkan pada gambar 10.

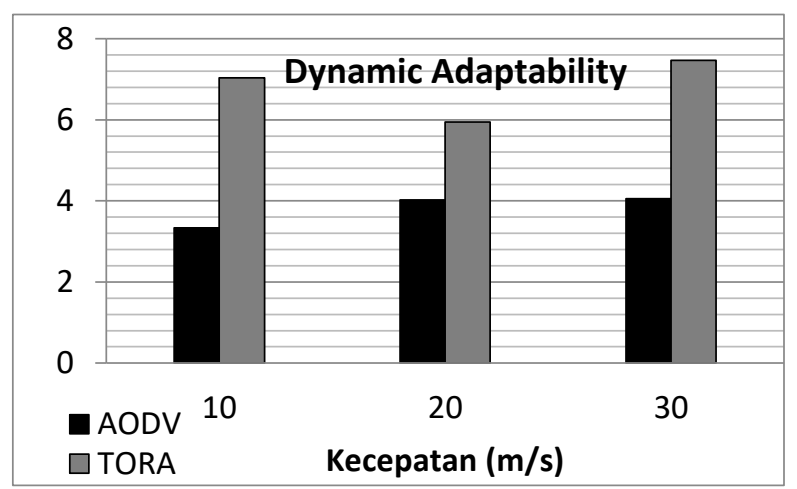

Gambar 10. Dynamic Adaptability skenario 1 


\subsection{Skenario 2}

Evaluasi kinerja pada skenario 2 ini akan membandingkan kinerja metode routing terdistribusi yang diterapkan pada dua protokol routing yang berbeda, yaitu protokol routing AODV dan protokol routing TORA. Hasil evaluasi dari kedua protokol routing ini akan menjadi acuan mengenai protokol routing yang tepat digunakan pada sistem komunikasi taktis untuk mengatasi permasalahan topologi jaringan, yaitu kemampuan suatu protokol routing untuk dapat beradaptasi terhadap perubahan topologi jaringan yang disebabkan oleh mobilitas node.

\subsubsection{End-to-End Delay}

Grafik pada gambar 11 menunjukkan hasil pengukuran end-to-end delay dari protokol routing AODV dan TORA yang menggunakan metode distributed routing. Pada protokol routing AODV, metode distributed dilakukan dengan cara menambahkan rute alternatif pada node sumber. Ketika rute utama pengiriman paket data terputus, node sumber tidak perlu melakukan proses pencarian rute kembali, tetapi dapat langsung menggunakan rute alternatif yang tersimpan didalam tabel routing node sumber. Sedangkan pada protokol routing TORA yang pada dasarnya telah memiliki kemampuan multiroute, penerapan metode distributed dilakukan dalam kriteria penentuan node penghubung (next hop). Dengan menggunakan metode ini, kriteria penentuan next hop juga berdasarkan nilai counter terendah dari node agent yang terdapat dalam cakupan komunikasi.

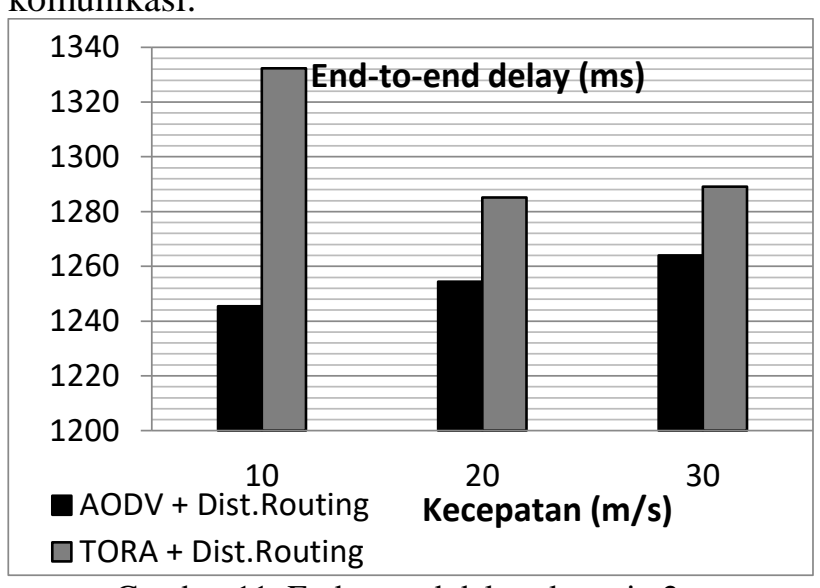

Gambar 11. End-to-end delay skenario 2

\subsubsection{Throughput}

Hasil pengukuran throughput pada skenario 2 ditunjukkan pada gambar 12. Grafik tersebut menunjukkan bahwa throughput yang dihasilkan oleh protokol routing AODV yang menggunakan metode routing terdistribusi cenderung lebih stabil untuk ketiga kecepatan yang berbeda. Grafik tersebut juga menunjukkan bahwa nilai throughput terbesar dihasilkan oleh protokol routing AODV. Meskipun kedua protokol routing tersebut memiliki rute alternatif dalam tabel routing nya, penambahan kriteria pencarian rute pada protokol routing TORA menyebabkan rendahnya throughput karena semakin banyak hop yang digunakan selama proses pengiriman paket data, loss yang dihasilkan juga akan semakin besar.

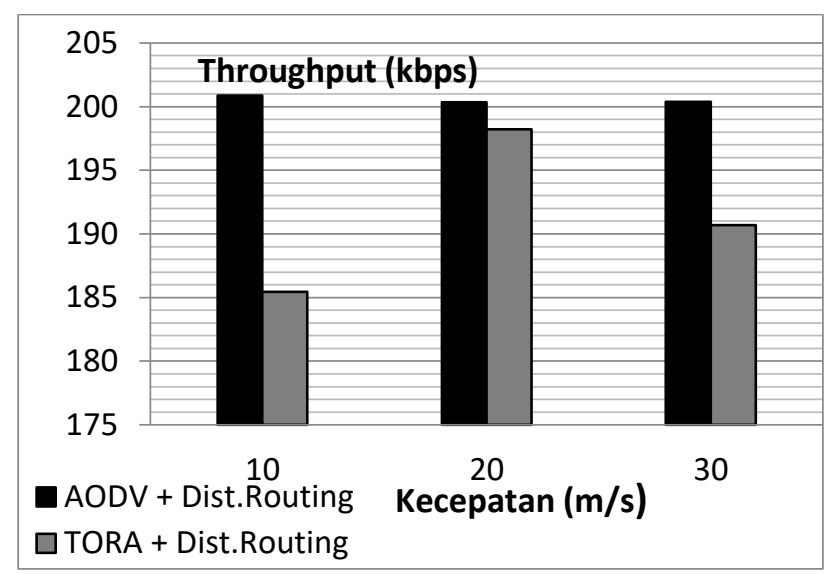

Gambar 12. Throughput skenario 2

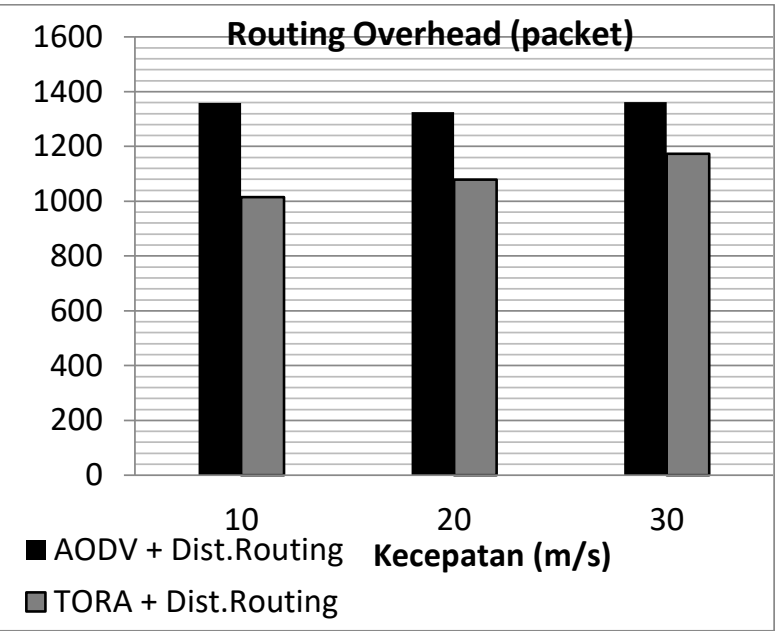

Gambar 13. Routing Overhead skenario 2

\subsubsection{Routing Overhead}

Pengukuran routing overhead pada metode routing terdistribusi untuk kedua protokol routing ditunjukkan pada gambar 13. Penambahan rute pada tabel routing AODV menyebabkan bertambahnya paket RREP yang dikirim oleh intermediate node yang memiliki informasi mengenai identitas node tujuan. Bertambahnya RREP yang diterima oleh node sumber menghasilkan overhead yang lebih tingi dari sebelumnya. Hal tersebut juga berlaku pada TORA yang secara alamiah memiliki kemampuan multiroute. Lebih besarnya routing overhead yang dihasilkan protokol routing AODV dikarenakan 
protokol routing ini membroadcast paket RREQ keseluruh node tetangganya secara kontinyu.

\subsubsection{Dynamic Adaptability}

Evaluasi kinerja dari metode routing terdistribusi untuk protokol routing AODV dan TORA yang paling penting adalah kemampuan protokol routing tersebut untuk dapat beradaptasi terhadap perubahan topologi jaringan yang disebabkan oleh mobilitas node.

Dengan menggunakan metode routing terdistribusi, kemampuan adaptasi dinamis yang lebih baik ditunjukkan oleh protokol routing AODV. Protokol routing AODV menghasilkan nilai throughput yang lebih besar dibandingkan TORA, begitu juga dengan waktu yang dibutuhkan untuk pencarian rute baru. Proses pencarian rute baru pada AODV lebih cepat karena kriteria pemilihan node yang digunakan next hop adalah node yang memiliki nilai hop count terkecil sedangkan protokol routing TORA tidak lagi berdasarkan nilai hop count terkecil tetapi juga memperhitungkan counter dari masing-masing node agent.

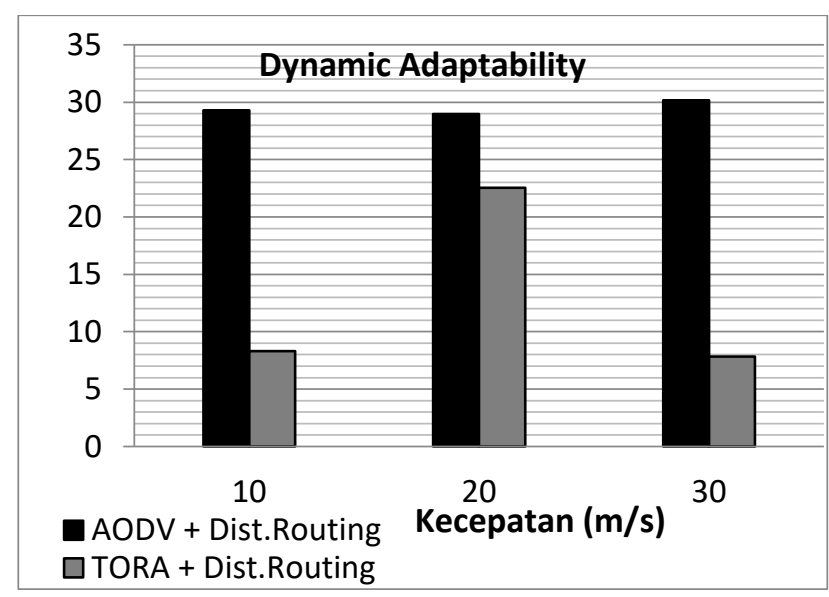

Gambar 14. Dynamic adaptability skenario 2

\section{Kesimpulam}

Berdasarkan analisa simulasi dari dua skenario yang berbeda terhadap parameter pengujian, maka dapat disimpulkan beberapa hal sebagai berikut:

- Protokol routing TORA konvensional menghasilkan nilai end-to-end delay yang lebih rendah dibandingkan protokol routing AODV karena memiliki kemampuan multiroute.

- Metode routing terdistribusi yang diterapkan pada protokol routing AODV dapat menurunkan waktu pengiriman paket data dari node sumber ke node tujuan dibandingan metode konvensional.

- Throughput yang dihasilkan oleh metode distributed routing pada AODV meningkat 2 kali dari metode konvensional. Penggunaan jalur alternatif pada AODV menyebabkan loss paket pada saat pengiriman paket data dapat diminimalisasi.

- Dibandingkan dengan metode konvensional, metode routing terdistribusi yang diterapkan pada protokol routing AODV lebih mampu untuk beradaptasi terhadap perubahan topologi dalam jaringan.

- Penambahan kriteria pencarian rute pada protokol routing TORA menyebabkan rendahnya nilai throughput, karena semakin banyak hop yang digunakan maka loss paket semakin besar.

- Dari pengujian yang dilakukan terhadap kedua protokol routing diatas, protokol routing AODV yang menggunakan metode routing terdistribusi dapat digunakan untuk mengatasi permasalahan jaringan. Namun protokol routing ini akan menghasilkan routing overhead yang lebih besar dibandingkan protokol routing TORA yang menggunakan routing terdistribusi.

\section{References}

Adam, N., Ismail, M.Y., Abdullah, J. (2010), "Effect of Node Density on Performances of Three MANET Routing Protocols,"International Conference on Electronic Devices, System and Application".

Burbank, J.L., Chimento, P.F., Haberman, B.K., Kasch, W.T. (November 2006),“ Key Challangesog Military Tactical Networking and The Elusive Promise of MANET Technology,“ IEEE Communication Magazine.

Elmasry, G.F. (October 2010), "A Comparative Review of Commercial vs Tactical Wireless Network," IEEE Communications Magazine".

Gohari, A.A., Pakbaz, R., Melliar-Smith, P.M., Moser, L.E., Rodoplu, V. (December 2011), "RMR: Reliability Map Routing for Tactical Mobile Ad Hoc Networks, “ IEEE Journal On Selected Areas In Communications, vol.29, no.10“.

Maseng, T., Landry, R., Young K. (October 2009), ” Military Communications, “ IEEE Communications Magazine.

Thoppian, M.R., Prakash, R. (January 2006), " A Distributed Protocols for Dynamic Address Assignment in Mobile Ad Hoc Networks, “ IEEE Transactions on Mobile Computing vol.5 no.1“. 